\title{
Gender Differences In Organizational Structure And Corporate Culture Preferences
}

\author{
Anila Amber Malik \\ \& \\ Sumayya Salim \\ Department of Psychology \\ University of Karachi
}

\begin{abstract}
The study aimed at establishing gender differences in the choice of organizational structure and corporate culture on a sample of 108 employees (males $=54$, females $=$ 54). It was seen that males prefer formalization and response culture while women give an edge to centralized organizations with an environment that promotes relationship culture. It was also noted that both males and females were least inclined to work in an organization with controlled culture.
\end{abstract}

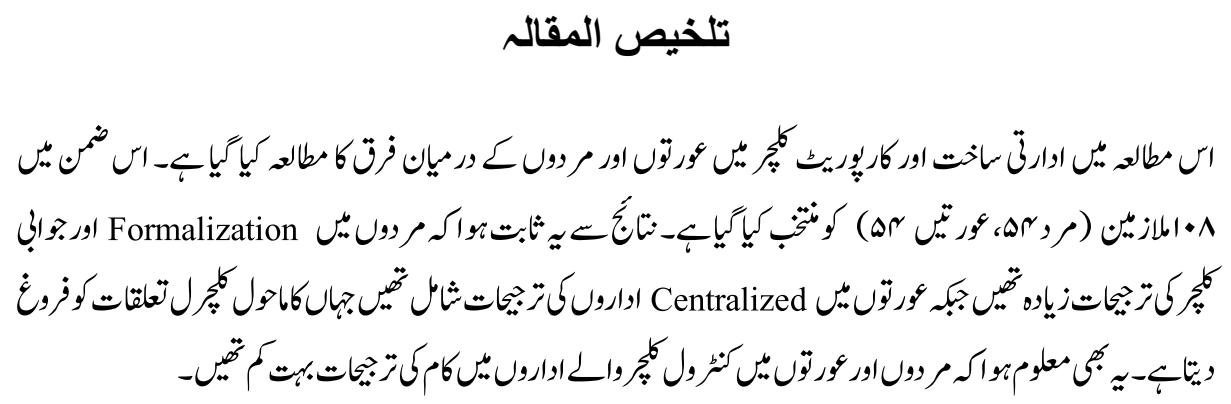

\section{Introduction}

Organizational behaviour focuses on those factors that have an impact on how individuals and groups act in organizations and how organizations manage their environment. Organizational structure is a formal way of work and reporting interaction that controls, co-ordinates, facilitates and motivates employees so that they co-operate and work collectively in order to achieve a goal. Whereas organizational culture is the informal set of values, attitudes and norms that govern the way people and group in an organization interact with each other and with people outside the organization like customer or clients and suppliers etc. (George \& Jones 1996).

Structure and culture of an organization must, encourage employees to work efficiently and to develop supportive work attitudes, and allow people and groups to cooperate and work together effectively. It implies a framework intended to: Link individuals in an established network of relationships so that authority, responsibility and communications 
can be controlled and assign the tasks required to fulfil the objective of the organization to suitable individuals or groups. Moreover give each individual or group the authority required to perform the allocated tasks, while controlling their behaviour and use of resources in the interests of the organization as a whole. Co-ordinate the objectives and activities of separate units, so that overall aims are achieved without gaps or overlaps in the flow of work.

And lastly facilitate the flow of work, information and other resources through the organization. The theory of contingency explain that the best structure for an organization will depend on so many contingent factors like organization's size, technical system, geographical location, personnel employed, the type of environment, activities in which the organization involved, and its business planning.

McShane \& Von Glinow (2003) describes three major factors of organizational structure.

A) Complexity: Complexity is the degree of differentiation of activities. It includes (1) spatial Complexity: geographical distribution of physical and human resources, (2) horizontal complexity i.e. the number of units across organization, and (3) vertical complexity i.e. the depth of organizational hierarchy. Vertical complexity is subdivided into flat and tall structures with reference to span of control - the number of subordinates who report to a superior official.

a) Tall Structure: A tall organization is one, which, in relation to its size, has a large number of levels of hierarchy. This allows a manager to maintain close control. Like every structure Tall hierarchies have some demerits as well. Its strict supervision blocks initiative, the same work passes through many hands and large administration increases overhead costs, while small groups enable team members to participate in decisionmaking, the process itself is slowed as the time it takes to send messages up and down the hierarchy increases. In addition, information passed from person to person can be distorted as messages become jumbled and managers naturally understand messages according to their own benefit. These problems further decrease the quality of decision making.

b) Flat Structures: A flat organization is one, which, in relation to its size, has a little number of hierarchical levels. It provides more opportunity for delegation and capable in terms of cost. In theory, a flat structure can facilitates communication between tactical apex and operating core. However, at some point it reduces effectiveness. That is, when span becomes too large, managers may only get a shallow idea of what goes on and employee performance suffers because supervisors no longer have the time to provide the necessary leadership and support. Flat organizations often require middle managers to convert the impressive vision of tactical apex into operational terms. 
B) Formalization: Formalization is "the use of rules and standard operating procedures to control an organization's activities," (George \& Jones 1996). The more an organization can rely on formalization to identify essential behaviors, the less it needs to use either direct supervision from the hierarchy or common adjustment. Formalization can result in lower operating costs and thus increased organizational performance. Once rules have been developed, they are economical to use and cost little to put into practice and retain. All that is required is that new employees be taught the appropriate rules to follow in certain situations. All organizations make broad use of rules because they are economical and valuable ways of co-ordinating activities both within and between functions and divisions.

C) Centralization: The concept includes only formal authority, that is, the rights innate in one's position. Typically, it's said that if top management makes the organization's key decisions with little or no input from lower-level personnel, then the organization is centralized. Since the decisions are made at one point, they are easier to coordinate. The senior managers can take a broad view of troubles and consequences. Centralization facilitates the senior management to symmetry the interests of various functions like the allocation of resources to all employee. The quality of decisions in such a firm is superior due to the senior managers' ability and skills. Comparatively tall hierarchy, centralized structures are possibly economical because of the reduced number of managers needed, thus reducing the costs of expenditure. So at the time of crisis, decisions can be taken more quickly at the center, without need to refer back. In spite of the great number of benefits, centralization may have some demerits as well. It overburdens the top management in terms of workload and hassle; the decision makers may not be aware of the local problems; decision making is slowed which may holdup growth of an organization in rapidly changing markets; the skills of the junior managers are not developed hampering managerial succession.

Cultural assumptions, values, attitudes, beliefs and norms influence the behavior of individuals, groups and organizations. Culture may be defined as "the collective programming of the mind which distinguishes the members of one category of people from another," (ACCA Study Text, 2004). Every organization has an exclusive culture that facilitates the expected behavior. Organizational culture is the "basic pattern of shared assumptions, values, and beliefs considered to be the correct way of thinking about and acting on problems and opportunities facing the organization," (McShane \& Von Glinow, 2003). An organization's culture consists of the goals an organization seeks to achieve, and the modes of behavior the organization encourages. Ideally, an organization's instrumental values help organization achieve its goals. Miles (2005) holds that corporate culture includes a company's reputation, environment as perceived from the outside and the "feeling" of the environment inside. Every organization has its exclusive culture or value set. 
McShane \& Von Glinow, (2003) suggests that a strong corporate culture enhances social control, and aids sense-making. However, strong cultures may create problems. Such organizations focus attention on one mental model, suppress dissenting values from subcultures, and culture content might be incompatible with the organization's context. Organizational culture determines leadership styles, employee morale and style of dress, length of the work day, support for life balance, and the ease and frequency of internal communication. ACCA Study Text (2004) describes some of the corporate culture types as follows:

a) Power Culture: Power and influence come out from an innermost source, perhaps the owner-directors of the business. The degree of formalization is limited, and there are few standards and ways like;

i. The organization is willing and capable of adapting quickly to meet change.

ii. Personal influence decreases as the size of an organization gets bigger. The power culture is therefore best suited to smaller entrepreneurial organizations, because here the leaders have direct communication and interactions with all employees.

iii. Personnel have to get on well with each other for this culture to work. These organizations are group of like-minded people introduced by the like-minded people, working on concerned initiative with personal contact rather than formal relationship. And that's why we call it club culture.

b) Role Culture: It is commonly known as 'bureaucracy' and is typically a large organization operating in a constant environment. Generally, this cultural type will have the following features.

i. Its structure is likely to be prescribed and stable, with functional departmentalization and clear lines of formal authority and responsibility.

ii. It will be process oriented, with considerable prescriptiveness about communication, procedure and behaviour. Individuals will be appointed to discharge defined responsibilities in accordance with the rules. Initiative may not be welcomed. Effective and efficient discharge of duty is the priority.

iii. The culture is not entrepreneurial and will be least susceptible to change. It takes its environment for granted but is very effective when not faced with sudden change.

This type of culture is a very much characteristic of military services, central and local government, nationalized monopolies and conservative businesses like banks and insurance companies.

c) Task Culture: Task culture is more responsive. It is based on a collective team work approach to changing circumstances. An organization with this culture will have the following features: 
i. Structure will be flexible, with project teams formed and adjusted as required. There will be small hierarchy or formal leadership responsibility since members will suppose to be specialists and experts in their own fields.

ii. The main concern will be results.

iii. There will be an expectation of high self satisfaction. Technical challenge and an opportunity to make a contribution will be valued highly.

This type of culture is visible in some professional practices, such as architects and engineers, in advertising agencies and in creative work such as film or media like television production.

d) Person Culture: Person culture or 'existential culture' is found in an organization whose purpose is to serve the interests of the employees within it. These organizations are not very common. Following are some of the features of person culture:

i. Management positions in these organizations are often lower in status. The professionals are labeled as secretaries, administrators, bursars, registrars or clerks.

ii. The organization depends on the abilities and skills of the individuals; management is derived from the consent of the managed, rather than the delegated authority of the owners.

iii. The members of such an organization value independence and achievement and may work more or less in isolation from their colleagues.

McShane \& Von Glinow, 2003 has identified and explained some of the types of culture in his Corporate Culture Preference Scale:

a) Control Culture: values the role of senior executives to lead the organization. Its goal is to keep everyone associated and under control.

b) Performance Culture: values individual and organizational performance and strives for effectiveness and efficiency.

c) Relationship Culture: values development and well-being. It considers open communication, fairness, teamwork, and sharing a vital part of organizational life.

d) Response Culture: values its ability to keep in harmony with the external environment, including being competitive and realizing new opportunities.

These culture types do not necessarily equate to specific organization types, though some styles of organization culture may accompany particular organizational structures. Also, it is quite possible for different cultures to prevail in different parts of the same organization, especially large ones with many departments and sites.

The present study aims at understanding the gender differences in corporate culture and organizational structure preferences. The concept of organizational culture has been 
researched for a variety of reasons, for example, the notion to improve quality and customer satisfaction, increase profits and performance, or implement a strategic change effort, (Ashkanasy, Wilderom and Peterson, 2000). Some researchers have tried to specify various relationships between gender and organizational culture in relation to many of the same issues. The fact that the interest in gender and its relationship to the culture of the organization has only recently materialized within organizational analysis does not mean that the connection is not present (Mills, 1988; Mills and Tancred, 1992).

In relation to this study, we look at gender differences in organizational structure and corporate culture preferences.

So the researchers hypothesized that there will be a difference between male and female with reference to organizational structure and corporate culture preference.

\section{Methodology}

\section{Sample}

The study was conducted on $108(\mathrm{~m}=54, \mathrm{f}=54)$ participants (age: above 20 years) from 55 organization of Pakistan, e.g. Cawasjee \& Sons, Jung office, Jinnah Hospital etc. The organizations are initially categorized as Tall Hierarchy, Formalization, and Centralization. The subjects came from different socio-economic backgrounds.

\section{Measures}

\section{Organizational Structure Preference Scale}

The scale consists of 15 items aimed at assessing a respondent's preference for Tall Hierarchy, Formalization, or Centralization in an organization (McShane \& Von Glinow, 2003). It provides four response categories, where $0=$ not at all, $1=$ a little, $2=$ somewhat, and 3 = very much.

\section{Corporate Culture Preference Scale}

McShane \& Von Glinow (2003) has presented the scale in form of 12 paired-items. The subjects are required to rate each pair of statement describing the organizational culture in which they prefer to work.

* Permission was sought from the author for the use of the tests. 


\section{Procedure}

The participants were instructed to rate themselves on the two scales. Means of this raw data were calculated which showed the gender differences in cultural and organizational preferences.

\section{Results}

Table 1

Means of Types of Organizational Structures: Tall Hierarchy, Formalization and Centralization

\begin{tabular}{|l|l|l|l|c|}
\hline \multirow{2}{*}{} & \multicolumn{4}{|c|}{ Means } \\
\cline { 2 - 5 } & Tall Hierarchy & Formalization & Centralization & Total \\
\hline Fales & 8.93 & 9.5 & 8.96 & 27.37 \\
\hline
\end{tabular}

Table I: Illustrates that male prefer formalized organizational structure whereas female prefer centralized organizational structure.

Table 2

Means of Types of Corporate Culture: Control, Performance, Relationship and Response Culture

\begin{tabular}{|l|c|c|c|c|c|}
\hline & \multicolumn{5}{|c|}{ Means } \\
\cline { 2 - 6 } & $\begin{array}{c}\text { Control } \\
\text { Culture }\end{array}$ & $\begin{array}{c}\text { Performance } \\
\text { Culture }\end{array}$ & $\begin{array}{c}\text { Relationship } \\
\text { Culture }\end{array}$ & $\begin{array}{c}\text { Response } \\
\text { Culture }\end{array}$ & Total \\
\hline Males & 2.07 & 3.09 & 3.17 & 3.5 & 11.81 \\
\hline Females & 1.78 & 2.69 & 4.52 & 3.32 & 11.91 \\
\hline
\end{tabular}

Table II: Illustrates that male prefer response culture whereas female prefer relationship culture.

\section{Discussion}

A negligible difference in male and female preference for organizational culture and structure has been noted. Men showed a slightly higher inclination for formalization with response culture. It may be said that they prefer to work with standard procedures, where the job incumbent has a minimum amount of discretion over what is to be done, when it is to be done, and how he should do it. Since an individual's discretion on the job is inversely related to the amount of behaviour in that job that is preprogrammed by the organization, the greater the standardization, the less input the employee has into how his work is to be done. Standardization not only eliminates the possibility of employees engaging in alternative behaviours, but it even removes the need for employees to consider alternatives. Often males in our society get employment only to cater the family's financial needs and so their interests in the jobs undertaken may not be very high leading them to prefer a job that requires innovation in the least. This preference for set 
rules may also be linked to their childhood. Maltz \& Borker's (1982) classic study on children's play suggests that games that boys play, e.g. football and war, are structured by goals and rules and there is little need to talk or organize relationships. The researchers also noted that boys' games are highly competitive not only between teams but also within teams. Thus, it comes as no surprise that men in the present study showed a preference - although minor - for response culture. Such a culture values competitiveness and broadens their horizons as they keep in touch with the ever changing world. Availing every new opportunity takes them up the promotional ladder rather quickly.

Females as opposed to males showed again an insignificant preference for a centralized structure with relationship culture in an organization. This highlights their preference for quality decisions for the betterment of the firm because higher authorities that are more trained and skilled in their sphere of activity take all the decisions in such a structure. The National Foundation for Women Business Owners (2003) also reported that women and men business owners have different management styles. Women are less hierarchical, may take more time when making decisions, seek more information, and are more likely to draw upon input from others, including fellow business owners, employees and subject-matter experts. Females are more likely to enjoy working in an organization where responsibilities, duties and fringe benefits are divided uniformly among employees. Centralization also gives some authority in daily decision making to the front line teams while senior executives set the overall goals.

According to the Lipman-Blumen, Jean, 1980 study females have reported relationship culture as a slightly more congenial work environment. Women emphasize on expressive work relationship, obtaining social support and friendship from ties to female coworkers and rely on relationship with male coworkers to gain access to instrumental resources, thus being effective in their job without forfeiting access to the social benefits . Further support for female's preference for relationship culture comes from physiology. The cerebral right hemisphere dominant in females is involved in the display (Bowers et al. 1993) and evaluation (Barod, 1993) of emotional expressions.

In spite of these gender differences both males and females showed least liking for control culture. This finding may benefit business leaders. It is clear that for a business to be successful, it is mandatory that it is consensual and participatory. Effective leaders should promote guiding and not controlling events and people (Toffler, 1980).

\section{Conclusion}

The results show a negligible difference in gender preferences in organizational structure and corporate culture. Males prefer to work in a formalized organization with a response 
culture, whereas women are slightly more inclined towards working in a centralized firm with a relationship culture.

\section{References}

ACCA Study Text (2004) Paper 1.3, Managing People. Professional Business Publications, Pak. Pp, 6-21, $47-57,318-319$.

Ashkanasy, N. M., Wilderom, C. P. M., \& Peterson, M.F. (2000) Handbook of organizational culture \& climate. Thousand Oaks: Sage Publications.

Borod, J.C. (1993) Cerebral mechanisms underlying facial, prosodic, and lexical emotional expression: A review of neuropsychological studies and methodological issues. Neuropsychology, 7: pp. 445463.

Bowers, D., Bauer, R.M., Heilman, K. (1993) The nonverbal affect lexicon: Theoretical perspectives from neuropsychological studies of affect perception. Neuropsychology, 7: pp. 433 - 444.

Brown, R. (2003) Gender Influences On Organizational Culture In Women Owned Businesses. A Research Paper Submitted in Partial Fulfillment of the Requirements for the Master of Science Degree in Training and Development to University of Wisconsin-Stout.

George, J.M. \& Jones, R.G. (1996) Understanding and Managing Organizational Behavior, $1^{\text {st }}$ Ed, Addison-Wesley Publishing, New York.

Hendrick, C. \& Hendrick, S.S. (2000) Close Relationships; A source book, USA, Sage Publications, pp. 304-305.

Lipman-Blumen, Jean (1980) "Female leadership in formal organizations: Must the female leader go formal?", in H. Leavitt, L. Pondy, and D. Boje (Eds.), Readings in Managerial Psychology, 3rd Ed. (pp. 341-362). Chicago, University of Chicago Press.

Maltz, D. \& Borker R. (1982) “A Cultural Approach to Male-Female Miscommunication” In J Gumperz(ed.) Language and Social identity, Cambridge University Press, Cambridge, pp 196-216.

McShane, S.L. \& Von Glinow, M.A. (2003) Organizational Behavior: Emerging Realities for the Workplace Revolution, McGraw-Hill Irwin. 
Miles, D. (2005) Knowing Your Corporate Culture and Hiring Employees Who Fit Saves Companies Thousands of Dollars, Miles Advises, The Miles/LeHane Group, Inc.

Mills, A. J. \& Tancred, P. (1992) Gendering Organizational Analysis, Newbury Park, Sage Publications.

Mills, A.J. (1988) Organization, Gender and Culture, Organization Studies, 9, 3, pp. 351369.

National Foundation of Women's Business Owners. (2002, March) Retrieved March 10, 2003, from Center for Women's Business Research. Access: http://www.nfwbo.org/key.html.

Toffler, Alvin (1980) The Third Wave, New York, William Morrow and Company, Inc.

Dr. Anila Amber Malik is Associate Professor in the Department of Psychology, University of Karachi.

Sumayya Salim is Research Scholar in the Department of Psychology, University of Karachi. 